\title{
Addressing post-stroke care in rural areas with Peru as a Case Study. Placing emphasis on evidence-based pragmatism
}

Authors: J. Jaime Miranda ${ }^{a, b}$, Miguel G. Moscoso ${ }^{a}$, Lijing L. Yan ${ }^{c, d}$, Francisco DiezCanseco ${ }^{\mathrm{a}}$, Germán Málaga ${ }^{\mathrm{a}, \mathrm{e}}$, Hector H. Garcia ${ }^{\dagger}$, Bruce Ovbiagele ${ }^{\mathrm{g}}$ 


\section{Abbreviations}

LMIC: Low and Middle income countries

SMS: Short messaging services 
Stroke is a major cause of death and disability, with most of its burden now affecting low- and middle-income countries (LMIC). People in rural areas of LMIC who have a stroke receive very little acute stroke care and local healthcare workers and family caregivers in these regions lack the necessary knowledge to assist them. Intriguingly, a recent rapid growth in cell-phone use and digital technology in rural areas has not yet been appropriately exploited for health care training and delivery purposes. What should be done in rural areas, at the community settinglevel, where access to healthcare is limited remains a challenge. We review the evidence on improving post-stroke outcomes including lowering the risks of functional disability, stroke recurrence, and mortality, and propose some approaches, to target post-stroke care and rehabilitation, noting key challenges in designing suitable interventions and emphasizing the advantages mHealth and communication technologies can offer. In the article, we present the prevailing stroke care situation and technological opportunities in rural Peru as a case study. As such, by addressing major limitations in rural healthcare systems, we investigate the potential of task-shifting complemented with technology to utilize and strengthen both community-based informal caregivers and community healthcare workers.

Keywords: Stroke, Task-shifting, mHealth, Implementation Science 


\section{Introduction}

2 Stroke affects 62 million people worldwide, $87 \%$ of whom live in low-and middle-income 3 countries (LMIC), ${ }^{1-3}$ imposing major societal and economic burdens. ${ }^{4}$ Each year in the US, 4 about 800,000 people experience a stroke and 220,000 die from it. ${ }^{5}$ Consequently, $24 \%$ of 5 survivors are discharged to inpatient rehabilitation facilities. ${ }^{6}$ Stroke costs the US $\$ 34$ billion 6 annually, including health care services, medications, and lost productivity. ${ }^{5}$ In Canada, 62,000 7 people experience a stroke each year and 6,500 stroke survivors access in-patient stroke 8 rehabilitation and stay a median of 30 days. $^{7}$ In contrast, for many LMIC, especially in rural 9 settings, access to appropriate stroke care and rehabilitation are substandard. In LMIC, stroke 10 fatality ranges between $18-35 \%{ }^{8,9}$ For instance, a sub-analysis of the INTERSTROKE study, ${ }^{10}$ 11 showed that Peruvian participants with a first-ever stroke had a $21 \%$ mortality and a $20 \%$ re12 stroke rate at one year, and less than $20 \%$ of stroke survivors completed a rehabilitation 13 program. ${ }^{11,12}$

\section{Burden of Stroke and Need for Optimal Post-Stroke Care}

Stroke is a leading cause of disability and death, including LMIC countries like Peru. ${ }^{12-14}$ However, while stroke mortality rates have recently decreased due to improved medical treatments, the number of individuals living with the residual effects of stroke is rising. ${ }^{15}$ Indeed, currently over $75 \%$ of patients survive a first stroke, and among these individuals, $25 \%$ are left with a minor disability and $40 \%$ experience moderate-to-severe disabilities. ${ }^{16}$ Beyond the lingering physical, psychological and social effects of an index stroke, up to $25 \%$ of stroke survivors experience recurrent strokes, ${ }^{17}$ and the morbidity and mortality after a recurrent stroke is more devastating than that of a primary stroke, with a near doubling of the 30-day fatality rate after a first recurrent stroke compared to a first-ever stroke. ${ }^{18}$. As well, in family-oriented societies where significant health expenditure is out-of-pocket, stroke dramatically changes the life not only of the stroke survivors but also of their family caregivers. In addition, for a large number of stroke patients living in rural areas, the care they receive is inadequate and far below evidence-based standards. $^{19}$

In Latin America, stroke is the fourth leading cause of years of life lost, and in Peru it ranks fifth: $^{20}$ there is no national stroke program and only three hospitals have stroke units and thrombolytic therapy. ${ }^{21}$ Stroke is listed as a leading cause of disease burden for national priority setting purposes. ${ }^{22}$ The consequences of stroke disproportionately affect rural populations where there is a severe shortage of neurologists and rehabilitation specialists, and where those 
few who receive rehabilitation are at risk of complications that need specialized care. ${ }^{23,24}$ People

34 living in rural areas are at a great disadvantage compared to urban areas: for example, the urban-rural income ratio is 2.4 in Peru (urban US\$ 362, rural \$150). ${ }^{25,26}$

\section{Limitations of rural healthcare in developing countries}

Most healthcare systems are acute-care oriented, specialist-centered, urban-located, and fragmented, and are thus ill prepared to deal with chronic conditions, especially in LMICs. ${ }^{27,28}$ For the vulnerable population of stroke patients in poorly resourced rural areas, secondary prevention and rehabilitation are largely unavailable and, where present, are far below evidence-based standards. ${ }^{29}$ To rely on specialists to provide such services is not only unrealistic but also unsustainable, particularly in settings where health systems' are fragmented and heavily focused on providing care for acute and infectious diseases rather than chronic conditions. ${ }^{30}$ Yet healthcare workers and family caregivers, who live in the same communities as the patients, lack the necessary knowledge, training, and tools to provide at least a basic but appropriate level of care.

Healthcare systems in resource-poor settings are plagued with many barriers to prevention and control of chronic conditions including fragmentation of care, over reliance on healthcare facilities, over burden of specialists in tertiary care, among others. The World Health Organization identifies six main building blocks of healthcare systems: service delivery, information and evidence, medical products and technology, health workforce, health financing, and leadership and governance. ${ }^{31}$

3 The chronic care model provides a systematic framework with six key elements-community, health system, self-management support, delivery system design, decision support, and clinical information systems-that are critical to effective management of chronic diseases. ${ }^{32}$ Addressing all six key elements is broadly relevant to most chronic conditions, where fatal and non-fatal outcomes bring a major share of global disability and burden. ${ }^{33}$ Focusing on poststroke care in rural settings highlights multiple challenges given it's role as a major cause of mortality, morbidity, disability, productivity loss, and poverty in LMICs, and because it's a condition encompassing multiple dimensions of health care, each with specific risk factors, associated health conditions, consequences, at various health services and community levels of the healthcare system. 


\section{The opportunity of technology and mHealth}

64 Rapid growth in cell-phone use, Internet connectivity, and digital health technology in lowresource countries and regions ${ }^{34}$ present new opportunities for improvements in healthcare delivery and population-based outcomes, ${ }^{35}$ including the engagement of frontline healthcare workers and community actors in mHealth-oriented activities. ${ }^{35-37}$ A systematic review aimed to describe approaches to improve mental health in rural areas found that the majority of interventions took advantage of technology in many ways such as telemedicine and videoconferencing in order to help professionals to provide care in remote areas. ${ }^{37}$

Cell phone usage has also been rising dramatically and reached high levels in many LMIC. Only in the last ten years, cell phone subscriptions (per 100 people) have increased from 20 to 110 in Peru and nearly to 180 in African Countries. ${ }^{38}$ By 2013, almost $80 \%$ of Peruvian households had at least one family member with access to a cell-phone. Interestingly, the largest increase in the 2012-2013 in mobile phone ownership was observed in rural areas. ${ }^{39}$ Usually the cost of sending short messaging services (SMS) is only charged to those who send it. In terms of planning interventions using such platforms, the evidence suggests that more than $95 \%$ of those with a cell phone can receive an SMS and more than $90 \%$ know how to read it, ${ }^{40}$ so people generally do not need training. Elderly patients report the daily use of cellphones for calls, ${ }^{41}$ and this was noted despite the fact that most participants stated having never used a computer $(78 \%)$, e-mail $(84 \%)$, or the Internet $(84 \%) .{ }^{41}$ Yet, the majority of this group $(70 \%)$ had at some time forgotten to take their medicine, $73 \%$ would like to be reminded to take their medication, and importantly $68 \%$ had a family member who could help them with access to information and communication technologies, signaling opportunities to work with caregivers or family contacts. ${ }^{41}$

Interventions using mHealth components, especially those oriented to primary prevention or those addressing behavior change, are complex interventions by nature, ${ }^{42-44}$ requiring working together with technology and engineering teams to develop mHealth platforms, as well as health communicators to develop appropriate and culturally-sensitive messages. ${ }^{45} \mathrm{~A}$ recently published randomized controlled trial to prevent the progression from prehypertension to hypertension was designed to test an mHealth approach, a tailored telephone contact followed by SMS, oriented to modify health behaviors, including weight reduction, and conducted in three Latin American countries. This study was a primordial prevention study where enrolled subjects from poor urban communities had normal levels of blood pressure. The results showed significant dose- 
response effects in weight reduction, up to $4.8 \mathrm{~kg} / \mathrm{m}^{2}$ among those who received $75 \%$ or more of the intervention, thereby signaling challenges in the uptake of complex interventions. ${ }^{40}$

In a similar vein, SMS provide both opportunities based on simplicity, reach and costs, yet from a health communications point of view, they also raise the need for context-specific and culturally-acceptable SMS to be tailored to an individual's risk profile and behavioral stages of change. For some, SMS should provide only one concept, use simple and direct language, and be understandable to lay people, ${ }^{45}$ something easier to be said than done.

Whilst technology and mHealth appear as suitable candidates to deploy stroke-related interventions, they require attention in their development. Technical barriers such as Internet connectivity in rural areas are of concern and could be overcome by working with engineering professionals to ensure mHealth tools reach target populations. Besides, assembling and testing the multiple components of a complex intervention for post-stroke care and rehabilitation will require the combination, in many cases, of expertise in behavioral psychology, technology and health communication in addition to clinical medicine and rehabilitation.

\section{Informal caregiving and access to rehabilitation}

Taking Peru as a case-study, a nationwide analysis of people living with disabilities showed that 1.6 million Peruvians have a disability, $40 \%$ of whom require assistance with daily living activities, and $95 \%$ of such assistance is provided by informal caregivers. ${ }^{46}$ An emphasis on the gaps that remain to reach coverage, at least contact coverage, there is a wide disadvantage for rural dwellers in access to rehabilitation services. First, over $95 \%$ of people with any disability know about the presence of healthcare and rehabilitation services in urban areas, yet only $43 \%$ of them know about the existence of rehabilitation services in rural areas. Second, the utilization of rehabilitation services is low, but even lower among people from rural vs. urban areas, i.e. $10 \%$ vs. $28 \%$. Thirdly, and elated to the later, $35 \%$ of individuals with disabilities in rural settings reported accessibility issues related to transportation, distance to rehabilitation centers and presence of physical barriers in health centers.

Reaching out to stroke survivors and their caregivers, in particular those who do not access healthcare or rehabilitation services is another challenge. A recent study focused on approaching those serving as a caregiver of a stroke survivor, the stroke event occurred at least 6 months prior to the study, had received medical attention for the acute episode within the public health system, and required assistance to perform daily activities as a result of the stroke. 
Of the 67 potential caregivers contacted, 23 were eligible, yet only 15 were finally interviewed. ${ }^{47}$ This experience suggests substantial challenges in reaching those stroke survivors and its caregivers who are in most need.

The experiences of informal caregivers of stroke survivors in a context where the health system does not provide them any training, financial support and mental health services indicate major burdens. ${ }^{47}$ Major burdens include emotional distress as a consequence of their relative's disabled condition, the need to see a professional to improve their mental health; and, the need to receive more information about how to take care of someone who suffered a stroke. ${ }^{47}$

\section{Ongoing studies in stroke care in underserved populations}

In high income settings, mobile health apps with educational content on stroke symptoms have been utilized to assist the lay public and healthcare providers to identify stroke, prompt emergency responses and promote risk assessment for timely recognition and treatment of stroke thus helping overcome delays in health seeking after stroke which is a prime barrier to optimal management of acute stroke. ${ }^{48-50}$

In resource-replete and rural settings, telemedicine based interventions, adapted to an mHealth based platform expedited access to safe and efficacious thrombolytic therapy with improved outcomes for ischemic stroke. ${ }^{51-53}$ The aforementioned data notwithstanding, it should be mentioned that despite the rapid growth of mobile health applications, there are still relatively few culturally-appropriate and sustainable stroke-specific $\mathrm{apps}^{54}$ and the overwhelming majority of published studies have focused on the pre-stroke or ultra-early stroke (within hours of onset) periods, not the post-stroke period (days, weeks, months after onset), the latter of which is the much more common presentation scenario in rural settings of LMIC. Enhancing post-stroke outcomes by optimizing secondary preventive care and rehabilitation via culturally-relevant mHealth interventions will likely be the most viable strategy for greatly reducing the burden of stroke in rural areas of LMIC. A recent systematic review and meta-analysis of randomized control clinical trials that evaluated the effect of mHealth on major stroke risk factors found that of 79 studies identified, 13 of them met eligibility criteria (Ovbiagele B, personal communication). Authors concluded that mHealth improved glycemic control and smoking abstinence rates, two factors that may lead to better stroke outcomes, but that there is a need for mHealth to be tested in modifying other premier risk factors for stroke including hypertension (Ovbiagele B, personal communication).

157 An ongoing study looking at the use of mHealth to improve hypertension control after stroke is 
the Phone-based Interventions under Nurse Guidance after stroke study (PINGS). ${ }^{55,56}$ PINGS is a pilot randomized controlled trial that seeks to show that a theoretical-model-based, mHealth technology-centered, multi-level integrated approach is effective in improving sustained blood pressure control among 60 recent Ghanaian stroke patients within one month of symptom onset. Blood pressure readings and medication adherence data are sent remotely to nurses by patients who will receive feedback motivational messages delivered by text messages based on levels of blood pressure control and adherence to therapy with targeted interventions coordinated by the nurse under a physician supervision in the intervention arm. A feasible and preliminarily effective PINGS intervention could lead to a larger more definitive efficacy/effectiveness RCT powered to look at clinical events. ${ }^{55,56}$

\section{Moving forward: Post-stroke care and rehabilitation in underserved rural areas}

\section{Emphasis on pragmatism}

171 Working on post-stroke care and rehabilitation with underserved populations and in rural areas requires addressing currently non-existent but much-needed practical tools and interventions at the community level, including task shifting. A myriad of interventions could be proposed, yet the absorptive capacity of rural areas, in other words the likelihood of implementing them, will be minimal given current shortcomings in various aspects. LMIC cannot afford to replicate the existing infrastructure of health systems in high-income settings, thus providing an opportunity for leapfrogging. ${ }^{30}$ Any intervention to be developed in post-stroke care should place emphasis on its pragmatism and its emphasis on external validity ${ }^{57}$ by developing and introducing simple and feasible ways to bring evidence-based post-stroke management, including preventive secondary care and rehabilitation, to rural areas traditionally underrepresented in research.

The potential of incorporating a technology-driven tool that facilitates integration across different tiers of healthcare facilities and the community is substantial. As such, the strategy may be exported as a feasible and highly cost-efficient model of healthcare worker and caregiver involvement rehabilitation that minimizes costs and can be provided in community settings, much needed to ensure high-quality care for underserved areas, as well as for other chronic diseases. In so doing, this opens an ideal opportunity to train LMIC-based scientists and international peers on hands-on approaches towards implementation science, with major exposures to this discipline early in their career development. ${ }^{58-62}$ 


\section{Evidence-based stroke rehabilitation}

After the occurrence of a stroke, multiple actions are deployed to provide acute care, prevent medical complications, implement rehabilitation, and prevent stroke recurrence. ${ }^{63}$ Multiple guidelines and reports show a strong body of evidence supporting activities to reduce mortality, to improve functionality, and to prevent recurrence of stroke. ${ }^{7,22,63-66}$ Among literature, stroke rehabilitation is oriented to restoring the functions lost due to stroke-mobility, language, dysphagia, and occupational skills-and is one of the main dimensions of stroke care. Early rehabilitation has proven to be effective at reducing mortality and improving function in daily life activities following an acute stroke. ${ }^{63}$ Community-based rehabilitation for stroke patients includes efforts to deliver rehabilitation to remote areas, including task-shifting activities, adaptation of tools for rehabilitation, monitoring of stroke evolution, and group activities. ${ }^{63}$

As important as is stroke rehabilitation, it also represents a big challenge when it comes to its implementation and testing. A major review highlighted that "stroke rehabilitation presents specific challenges for research and for the application of evidence-based practice [...] interventions tend to be complex and contain several interrelated components [and] treatments might target several different problems from relieving very specific impairments to improving activity and participation. Interventions can occur at different points on a continuum of complexity ranging between highly complex treatments and specific treatments." 26

\section{Evidence-based home-based stroke rehabilitation}

Home-based rehabilitation care is efficacious at preventing deterioration and improving ability to undertake daily life activities, ${ }^{67}$ and rehabilitation at home also accelerates discharge without affecting health outcomes in stroke patients. ${ }^{68} \mathrm{~A}$ minimum package of evidence-based homebased interventions could be pursued focusing on:

212 i) Sub-acute stage of stroke: After patient discharge, early mobilization provided by 213 physiotherapist or nurses has proved to decrease mortality rates. ${ }^{69-71}$ To date, no consensus 214 about dose of mobilization has been achieved. Whilst the AVERT trial concludes that high 215 doses of very early mobilization, within $24 \mathrm{hrs}$ of stroke onset, could be harmful for stroke 216 patients, ${ }^{72}$ this does not preclude initiating the involvement of caregivers and primary health 217 care workers in learning about the importance and types of mobilization.

ii) Chronic stage of stroke: After 3 months of the index stroke, the objective is to recover basic motor functions to increase independence in patients. ${ }^{73}$ The task-specific approach has a level 
A of evidence as it pragmatically combines problem-solving activities with daily life activities and physical exercises, and has proven to be effective in recovery of gait skills and trunk stability, ${ }^{74,75}$ but there is conflicting evidence about the recovery of arm functions. ${ }^{76}$

iii) For both sub-acute and chronic stages, intensive training is recommended to condition disused muscles, foster function recovery and to prevent problems related to immobility such as deterioration, risk of fractures, recurrent stroke, or premature mortality. ${ }^{77}$

A home-based oriented rehabilitation requires not only the involvement of physical therapists or healthcare providers, but also the direct participation of caregivers.

\section{Evidence-based secondary prevention}

Acknowledging that not all health services are available in rural settings, a minimum package of evidence-based secondary preventive care interventions is warranted. This shall include the identification of acute symptoms signaling occurrence of stroke or complications, identification and avoidance of risk conditions and actions, use of evidence-based affordable and available medications and fostering adequate social involvement. ${ }^{78-81}$ Systolic blood pressure is the single most important modifiable risk factor for stroke recurrence and is also sensitive to improvement in lifestyle and anti-hypertensive care. ${ }^{82}$ Reduction of high systolic blood pressure is a recommended therapeutic target beyond the acute phase for all stroke survivors to prevent recurrent stroke, regardless of type, timing, or severity of stroke. Expert consensus guidelines recommend that secondary preventive therapies and rehabilitation after stroke should be started soon after onset of symptoms and adhered to persistently to reduce risk of recurrent strokes, as well as facilitate re-integration of stroke survivors back into the society. ${ }^{82}$

\section{Emphasis on implementation science}

Addressing post-stroke care in rural areas will require engagement of policy makers and other stakeholders. ${ }^{60}$ The identification of potential facilitators and barriers not only for developing suitable interventions, but also for is implementation, is also needed ${ }^{83}$ Ensuring sufficient expertise within existing research teams in conducting mixed-methods studies and developing complex interventions will be crucial, including familiarity with hybrid effectivenessimplementation designs. ${ }^{59}$ Implementation outcomes such as acceptability, adoption, appropriateness, feasibility, fidelity and costs, as well as sustainability will be important to be defined and captured. ${ }^{61,62}$ It is anticipated that "hybrid studies require more research expertise and personnel, and larger budgets, than non-hybrid designs." ${ }^{59}$ This tradeoff considers 
4251 anticipated benefits by testing in real-world situations what works and for whom..$^{61,83-85}$ 6

7252

8

61 


\section{Anticipating challenges in designing future studies}

\section{Context matters}

Understanding context and needs for the implementation of adequate, sustainable, appropriate, evidence-based responses to stroke care in rural settings matters. Studies of barriers and facilitators using rapid assessment tools to gauge the readiness of existing care systems would be informative. This type of studies could enhance our understanding of provider and user current ongoing practices and views in relation to secondary prevention, adherence to medication, accessibility to rehabilitation services, and views about home-based rehabilitation including the training required. The assessment of current service delivery infrastructures, how they work and what are their most and least appreciated features, from the point of view of patient and caregivers are important. As guidance, among several other tools, the WHO's Six Building Blocks framework ${ }^{86}$ could be used as an analytical framework for its simple and universal approach to health system assessment. ${ }^{87}$ The framework describes each health system through the following components: a) information; b) leadership and governance; c) financing; d) health workforce; e) service delivery; f) medical products, vaccines and technologies. Each of these components includes relevant topics about health system performance.

\section{User-centered designs}

The implementation of post-stroke care in rural settings requires a strong evidence-based approach paired with engagement with its end-users. Implementation strategies amenable to the introduction of task shifting and community-oriented components may be needed. In so doing, a user-centered design focusing on the adaptation of materials for training and the development of technology including usability testing are needed.

Co-design workshops organized with PHWs, nurses, caregivers, and patients will help to obtain their input on the design of the various components of a potential intervention. There is a plethora of stroke-related materials to use, ${ }^{78-81,88-90}$ which will need refining, simplification, and integration with ease for its users, potentially patients, caregivers and community healthcare workers. Technology will be key in the creation or adaptation of algorithms that contain both knowledge and decision support, and can be paired with capacities to collect patient data for monitoring and performance evaluation. Usability evaluation techniques and tools, see for example http://www.usability.gov/, will also be needed to guarantee end-user's engagement. 
Worth mentioning, communities' inherent beliefs about health will have to be identified and understood as they may prevent people to accept different care from what they are accustomed. An ethnographic study conducted in rural Dominican Republic reported that inhabitant's cultural

\section{Targeting incident vs. prevalent stroke cases}

In rural areas, investigators should be aware of the tension in addressing incident vs. prevalent stroke cases. The effect of the intervention is likely to be larger among new patients than prevalent cases. The risk of recurrent stroke is highest during the first 90 days after an index stroke and longitudinal studies indicate that approximately 1 out of every 2 recurrences occurring in the first year occurs within the first 90 days. ${ }^{92}$ While focusing on newly onset stroke has the advantage of achieving larger effect sizes from the intervention, from a pragmatic implementation research perspective, it will ignore a much larger number of patients with an existing stroke.

\section{Targeting stroke subtypes}

The neurology literature describes differential recoveries according to the type of stroke, being less favorable in hemorrhagic strokes. ${ }^{93-95}$ But this dichotomy is also observed in various scenarios within the stroke field - the same differential outcome is observed within ischemic stroke subtypes, e.g. small vessel has better outcome than large vessel or cardioembolic strokes, younger patients have better outcomes than older patients, stroke patients with diabetes have worse outcomes than those without diabetes, etc. In reality, most rural communities do not have access to neurologists to address such detailed triaging and decisionmaking. Placing an emphasis on pragmatism, and on the provision of simple evidence-based recommendations could guarantee access to some rehabilitation to and post-stroke care to all stroke cases.

\section{When to start? It is never too late}

309 Many barriers exist for the provision of acute stroke care, and more so in rural areas. The AVERT trial showed no marked differences with the introduction of very early mobilization in hospitals, ${ }^{72}$ providing an opportunity to initiate some rehabilitation. Challenges also remain in many high-income settings where many patients do not receive a prescription for a statin or blood-pressure-lowering drug at one-month after the index stroke case ${ }^{96-99}$ despite their demonstrated benefit. ${ }^{96,100}$ This period has the additional advantage of accommodating to the 
new household structures, including the identification of those who will assume on a caregiving 6316 role.

\section{Conclusions}

As noted, stroke often has an adverse impact on patient dexterity, communication, and cognition which serves as a barrier to ready self-adherence to evidence-based post-stroke secondary preventive care and rehabilitation. This situation is further compounded in LMIC, especially the rural areas of these countries, where local healthcare workers and family caregivers lack the necessary knowledge, training, and tools to provide optimal stroke care to stroke survivors. Fortunately, the rapid growth in cell-phone use, Internet connectivity, and digital health technology in rural areas of LMIC, might be appropriately exploited for health care training and delivery purposes, to improve post-stroke outcomes in these regions. Expert consensus guidelines recommend that secondary preventive therapies and rehabilitation after stroke should be started soon after onset of symptoms and adhered to persistently to reduce risk of recurrent strokes, as well as facilitate re-integration of stroke survivors back into the society. ${ }^{82}$ The achievement of these goals depends on a coordinated and multi-disciplinary team effort involving several health professionals and the stroke patient/caregiver, which might best be coordinated using mHealth approaches and immediate stakeholders like caregivers. Careful patient selection, focused culturally-appropriate mHealth interventions, and accommodation for practicality, targeting key aspects of the post-stroke care continuum, should allow for greater availability and accessibility to, and sustainability of evidence-based stroke care in these highly stroke burdened areas.

Before mHealth interventions can gain widespread integration and sustained application in routine stroke care, some key issues need to be resolved. For example, it is not clear which specific aspects of stroke care that mHealth offer would produce the most profound benefits for patients/caregivers and healthcare providers. Resolving this key question will necessitate the conduct of several studies aimed at assessing targeted components of post-stroke care to derive high-level evidence-based data to inform policy adoption. It is expected that App developers would need to work closely and responsively with stroke patients, healthcare providers, system administrators, public health personnel, and researchers to fine tune interventions to 1) be adaptable in various residential and cultural settings; and 2) be screened by regulatory bodies to prevent unintended occurrences such as incorrect information and medical errors. These approaches would be in accord with expert recommendations on the use 
4347 of mobile devices, social media and crowdsourcing as digital strategies to improve care of 6348 individuals with vascular disease. ${ }^{101}$

7

8 


\section{Acknowledgements}

7350 To Katie Sacksteder, Daniel Guevara and Romina Ríos for their comments in earlier versions of 8351 this manuscript. 


\section{Funding}

7353 JJM acknowledges receiving current and past support from the Consejo Nacional de Ciencia, 8354 Tecnología e Innovación Tecnológica (CONCYTEC), DFID/MRC/Wellcome Global Health Trials (MR/M007405/1), Fogarty International Center (R21TW009982), Grand Challenges Canada (0335-04), International Development Research Center Canada (106887, 108167), InterAmerican Institute for Global Change Research (IAI CRN3036), National Heart, Lung and Blood Institute (5U01HL114180, HHSN268200900028C), National Institute of Mental Health (1U19MH098780), Swiss National Science Foundation (40P740-160366), Universidad Peruana Cayetano Heredia, and the Wellcome Trust (074833/Z/04/A, WT093541AIA, 103994/Z/14/Z). Dr Ovbiagele is supported by National Institutes of Neurological Disorders and Stroke (R21NS094033). Dr. Yan is partially supported by the National Natural Sciences Foundation of 363 China (71233001 and 71490732) and the DFID/MRC/Wellcome Trust/ESRC (MR/N015967/1). 


\section{References}

1. National Institute of Statistics and Informatics. Evolución de la pobreza monetaria 20092013. Technical Report, 2014. http://www.inei.gob.pe/media/cifras de pobreza/informetecnico.pdf (accessed 30 Dec 2015).

2. Strong K, Mathers C, Bonita R. Preventing stroke: saving lives around the world. The Lancet Neurology 2007; 6(2): 182-7.

3. Yan LL, Li C, Chen J, et al. Prevention, management, and rehabilitation of stroke in lowand middle-income countries. eNeurologicalSci 2016; 2: 21-30.

4. Bernabe-Ortiz A, Carrillo-Larco RM, Gilman RH, Checkley W, Smeeth L, Miranda JJ. Contribution of modifiable risk factors for hypertension and type-2 diabetes in Peruvian resource-limited settings. Journal of epidemiology and community health 2016; 70(1): 49-55.

5. Mozaffarian D, Benjamin EJ, Go AS, et al. Heart disease and stroke statistics--2015 update: a report from the American Heart Association. Circulation 2015; 131(4): e29-322.

6. Buntin MB, Colla CH, Deb P, Sood N, Escarce JJ. Medicare spending and outcomes after postacute care for stroke and hip fracture. Med Care 2010; 48(9): 776-84.

7. Hebert D, Lindsay MP, Mclntyre A, et al. Canadian stroke best practice recommendations: Stroke rehabilitation practice guidelines, update 2015. Int J Stroke 2016; 11(4): 459-84.

8. Feigin VL, Forouzanfar MH, Krishnamurthi R, et al. Global and regional burden of stroke during 1990-2010: findings from the Global Burden of Disease Study 2010. Lancet (London, England) 2014; 383(9913): 245-54.

9. Feigin VL, Lawes CM, Bennett DA, Barker-Collo SL, Parag V. Worldwide stroke incidence and early case fatality reported in 56 population-based studies: a systematic review. The Lancet Neurology 2009; 8(4): 355-69.

10. O'Donnell MJ, Xavier D, Liu L, et al. Risk factors for ischaemic and intracerebral haemorrhagic stroke in 22 countries (the INTERSTROKE study): a case-control study. Lancet (London, England) 2010; 376(9735): 112-23.

11. Alvarado-Dulanto CM, Lazo Mde L, Loza-Herrera JD, Malaga G. [One year prognosis after suffering the onset of cerebrovascular disease in patients from a public hospital in Lima, Peru]. Rev Peru Med Exp Salud Publica 2015; 32(1): 98-103.

12. Davalos LF, Malaga G. [Stroke in Peru: a forgotten and unattended prevalent disease]. Rev Peru Med Exp Salud Publica 2014; 31(2): 400-1.

13. Castaneda-Guarderas A, Beltran-Ale G, Casma-Bustamante R, Ruiz-Grosso P, Malaga G. [Registry of patients with stroke stated in a public hospital of Peru, 2000-2009]. Rev Peru Med Exp Salud Publica 2011; 28(4): 623-7.

14. Davalos LF, Málaga G. [Stroke in Peru: a forgotten and unattended prevalent disease]. Rev Peru Med Exp Salud Publica 2014; 31(2): 400-1. 
15. Ovbiagele B, Goldstein LB, Higashida RT, et al. Forecasting the future of stroke in the United States: a policy statement from the American Heart Association and American Stroke Association. Stroke 2013; 44(8): 2361-75.

16. Prevalence and Most Common Causes of Disability Among Adults --- United States, 2005 MMWR Morb Mortal Wkly Rep 2009; 58(16): 421-6.

17. Go AS, Mozaffarian D, Roger VL, et al. Executive summary: heart disease and stroke statistics--2014 update: a report from the American Heart Association. Circulation 2014; 129(3): 399-410.

18. Hardie K, Hankey GJ, Jamrozik K, Broadhurst RJ, Anderson C. Ten-year risk of first recurrent stroke and disability after first-ever stroke in the Perth Community Stroke Study. Stroke 2004; 35(3): 731-5.

19. Norrving B, Kissela B. The global burden of stroke and need for a continuum of care. Neurology 2013; 80(3 Suppl 2): S5-12.

20. Global, regional, and national age-sex specific all-cause and cause-specific mortality for 240 causes of death, 1990-2013: a systematic analysis for the Global Burden of Disease Study 2013. Lancet (London, England) 2015; 385(9963): 117-71.

21. Avezum A, Costa-Filho FF, Pieri A, Martins SO, Marin-Neto JA. Stroke in Latin America: Burden of Disease and Opportunities for Prevention. Global heart 2015; 10(4): 323-31.

22. Walker MF, Sunnerhagen KS, Fisher RJ. Evidence-based community stroke rehabilitation. Stroke 2013; 44(1): 293-7.

23. Dromerick A, Reding M. Medical and neurological complications during inpatient stroke rehabilitation. Stroke 1994; 25(2): 358-61.

24. Roth EJ, Lovell L, Harvey RL, Heinemann AW, Semik P, Diaz S. Incidence of and risk factors for medical complications during stroke rehabilitation. Stroke 2001; 32(2): 523-9.

25. Peiris D, Praveen D, Johnson C, Mogulluru K. Use of mHealth systems and tools for non-communicable diseases in low- and middle-income countries: a systematic review. Journal of cardiovascular translational research 2014; 7(8): 677-91.

26. Langhorne P, Bernhardt J, Kwakkel G. Stroke rehabilitation. Lancet (London, England) $2011 ;$ 377(9778): 1693-702.

27. Daar AS, Singer PA, Persad DL, et al. Grand challenges in chronic non-communicable diseases. Nature 2007; 450(7169): 494-6.

28. Atun R. Transitioning health systems for multimorbidity. Lancet (London, England) 2015; 386(9995): 721-2.

29. Rahiman A, Saver JL, Porter V, et al. In-hospital initiation of secondary prevention is associated with improved vascular outcomes at 3 months. J Stroke Cerebrovasc Dis 2008; 17(1): 5-8. 
30. World Economic Forum. Health Systems Leapfrogging in Emerging Economies. Geneva: WEF, 2014.

31. Beratarrechea A, Lee AG, Willner JM, Jahangir E, Ciapponi A, Rubinstein A. The impact of mobile health interventions on chronic disease outcomes in developing countries: a systematic review. Telemedicine journal and e-health : the official journal of the American Telemedicine Association 2014; 20(1): 75-82.

32. Bodenheimer T, Wagner EH, Grumbach K. Improving primary care for patients with chronic illness: the chronic care model, Part 2. Jama 2002; 288(15): 1909-14.

33. Global, regional, and national incidence, prevalence, and years lived with disability for 301 acute and chronic diseases and injuries in 188 countries, 1990-2013: a systematic analysis for the Global Burden of Disease Study 2013. Lancet (London, England) 2015; 386(9995): 743800.

34. Dromerick AW, Gibbons MC, Edwards DF, et al. Preventing recurrence of thromboembolic events through coordinated treatment in the District of Columbia. Int $J$ Stroke $2011 ; 6(5): 454-60$.

35. Labrique AB, Vasudevan L, Kochi E, Fabricant R, Mehl G. mHealth innovations as health system strengthening tools: 12 common applications and a visual framework. Global health, science and practice 2013; 1(2): 160-71.

36. Agarwal S, Perry HB, Long LA, Labrique AB. Evidence on feasibility and effective use of mHealth strategies by frontline health workers in developing countries: systematic review. Tropical medicine \& international health : TM \& IH 2015; 20(8): 1003-14.

37. Hoeft TJ, Fortney JC, Patel V, Unutzer J. Task-Sharing Approaches to Improve Mental Health Care in Rural and Other Low-Resource Settings: A Systematic Review. J Rural Health 2017.

38. International Telecommunication Union, World Telecommunication/ICT Development Report and database. Mobile cellular subscriptions (per 100 people). http://data.worldbank.org/indicator/IT.CEL.SETS.P2 (accessed 11 Jan 2017).

39. Ovbiagele B, Lyden PD, Saver JL, Collaborators V. Disability status at 1 month is a reliable proxy for final ischemic stroke outcome. Neurology 2010; 75(8): 688-92.

40. Rubinstein A, Miranda JJ, Beratarrechea A, et al. Effectiveness of an mHealth intervention to improve the cardiometabolic profile of people with prehypertension in lowresource urban settings in Latin America: a randomised controlled trial. Lancet Diabetes Endocrinol 2016; 4(1): 52-63.

41. Rivas-Nieto AC, Malaga G, Ruiz-Grosso P, Huayanay-Espinoza CA, Curioso WH. [Use and perceptions of information and communication technologies in patients with hypertension, dyslipidemia or diabetes in a national hospital in Lima, Peru]. Rev Peru Med Exp Salud Publica 2015; 32(2): 283-8.

42. Craig P, Dieppe P, Macintyre S, Michie S, Nazareth I, Petticrew M. Developing and evaluating complex interventions: the new Medical Research Council guidance. BMJ 2008; 337 : 
a1655.

477

43. Moore GF, Audrey S, Barker M, et al. Process evaluation of complex interventions: Medical Research Council guidance. BMJ 2015; 350: h1258.

44. Hoffmann TC, Glasziou PP, Boutron I, et al. Better reporting of interventions: template for intervention description and replication (TIDieR) checklist and guide. BMJ 2014; 348: g1687.

45. Diez-Canseco F, Zavala-Loayza JA, Beratarrechea A, et al. Design and Multi-Country Validation of Text Messages for an mHealth Intervention for Primary Prevention of Progression to Hypertension in Latin America. JMIR mHealth and uHealth 2015; 3(1): e19.

46. Bernabe-Ortiz A, Diez-Canseco F, Vasquez A, Miranda JJ. Disability, caregiver's dependency and patterns of access to rehabilitation care: results from a national representative study in Peru. Disability and rehabilitation 2015: 1-7.

47. Pesantes MA, Brandt LR, Ipince A, Miranda JJ, Diez-Canseco F. An exploration into caring for a stroke-survivor in Lima, Peru: Emotional impact, stress factors, coping mechanisms and unmet needs of informal caregivers. eNeurologicalSci 2017; 6: 33.50.

48. Dubey D, Amritphale A, Sawhney A, Amritphale N, Dubey P, Pandey A. Smart phone applications as a source of information on stroke. J Stroke 2014; 16(2): 86-90.

49. Nam HS, Heo J, Kim J, et al. Development of smartphone application that aids stroke screening and identifying nearby acute stroke care hospitals. Yonsei Med J 2014; 55(1): 25-9.

50. You JS, Park S, Chung SP. Mobile message for a better stroke recognition: the new concept of national campaign. Stroke 2008; 39(2): e42; author reply e3.

51. Bagot KL, Cadilhac DA, Hand PJ, Vu M, Bladin CF. Telemedicine expedites access to optimal acute stroke care. Lancet (London, England) 2016; 388(10046): 757-8.

52. Belt GH, Felberg RA, Rubin J, Halperin JJ. In-Transit Telemedicine Speeds Ischemic Stroke Treatment: Preliminary Results. Stroke 2016; 47(9): 2413-5.

53. Sharma S, Padma MV, Bhardwaj A, Sharma A, Sawal N, Thakur S. Telestroke in resource-poor developing country model. Neurol India 2016; 64(5): 934-40.

54. Singer J, Levine SR. Stroke and technology: prescribing mHealth apps for healthcare providers, patients and caregivers - a brief, selected review. Future Neurology 2016; 11(2): $109-12$.

55. Ovbiagele B. Phone-based intervention under nurse guidance after stroke: concept for lowering blood pressure after stroke in Sub-Saharan Africa. J Stroke Cerebrovasc Dis 2015; 24(1): 1-9.

56. Sarfo FS, Treiber F, Jenkins C, et al. Phone-based Intervention under Nurse Guidance after Stroke (PINGS): study protocol for a randomized controlled trial. Trials 2016; 17(1): 436.

57. Rothwell PM. External validity of randomised controlled trials: "to whom do the results of this trial apply?". Lancet (London, England) 2005; 365(9453): 82-93. 
58. Carroll C, Patterson M, Wood S, Booth A, Rick J, Balain S. A conceptual framework for implementation fidelity. Implementation science : IS 2007; 2: 40.

59. Curran GM, Bauer M, Mittman B, Pyne JM, Stetler C. Effectiveness-implementation hybrid designs: combining elements of clinical effectiveness and implementation research to enhance public health impact. Med Care 2012; 50(3): 217-26.

60. Damschroder LJ, Aron DC, Keith RE, Kirsh SR, Alexander JA, Lowery JC. Fostering implementation of health services research findings into practice: a consolidated framework for advancing implementation science. Implementation science : IS 2009; 4: 50.

61. Peters DH, Adam T, Alonge O, Agyepong IA, Tran N. Implementation research: what it is and how to do it. BMJ 2013; 347: f6753.

62. Proctor E, Silmere H, Raghavan R, et al. Outcomes for implementation research: conceptual distinctions, measurement challenges, and research agenda. Adm Policy Ment Health 2011; 38(2): 65-76.

63. Evidence-Based Review of Stroke Rehabilitation. Evidence Reviews. http://www.ebrsr.com/evidence-review (accessed 27 May 2016).

64. Alberts MJ, Easton JD. Stroke Best Practices: a team approach to evidence-based care. J Natl Med Assoc 2004; 96(4 Suppl): 5S-20S.

65. Lindsay P, Furie KL, Davis SM, Donnan GA, Norrving B. World Stroke Organization global stroke services guidelines and action plan. Int J Stroke 2014; 9 Suppl A100: 4-13.

66. Rodin M, Saliba D, Brummel-Smith K, American Geriatrics Society Clinical Practice C, Department of Veterans Affairs/Department of D. Guidelines abstracted from the Department of Veterans Affairs/Department of Defense clinical practice guideline for the management of stroke rehabilitation. J Am Geriatr Soc 2006; 54(1): 158-62.

67. Legg L, Langhorne P, Outpatient Service Trialists. Rehabilitation therapy services for stroke patients living at home: systematic review of randomised trials. Lancet (London, England) 2004; 363(9406): 352-6.

68. Anderson C, Rubenach S, Mhurchu CN, Clark M, Spencer C, Winsor A. Home or hospital for stroke rehabilitation? results of a randomized controlled trial : I: health outcomes at 6 months. Stroke 2000; 31(5): 1024-31.

69. Bernhardt J, English C, Johnson L, Cumming TB. Early mobilization after stroke: early adoption but limited evidence. Stroke 2015; 46(4): 1141-6.

70. Maulden SA, Gassaway J, Horn SD, Smout RJ, DeJong G. Timing of initiation of rehabilitation after stroke. Arch Phys Med Rehabil 2005; 86(12 Suppl 2): S34-S40.

71. Zhang WW, Speare S, Churilov L, Thuy M, Donnan G, Bernhardt J. Stroke rehabilitation in China: a systematic review and meta-analysis. Int J Stroke 2014; 9(4): 494-502.

72. Avert Trial Collaboration group, Bernhardt J, Langhorne P, et al. Efficacy and safety of very early mobilisation within $24 \mathrm{~h}$ of stroke onset (AVERT): a randomised controlled trial. 
73. Dobkin BH. Strategies for stroke rehabilitation. The Lancet Neurology 2004; 3(9): 52836.

74. van de Port IG, Wood-Dauphinee S, Lindeman E, Kwakkel G. Effects of exercise training programs on walking competency after stroke: a systematic review. Am J Phys Med Rehabil 2007; 86(11): 935-51.

75. Wevers L, van de Port I, Vermue M, Mead G, Kwakkel G. Effects of task-oriented circuit class training on walking competency after stroke: a systematic review. Stroke 2009; 40(7): 2450-9.

76. Bosch J, O'Donnell MJ, Barreca S, Thabane L, Wishart L. Does Task-Oriented Practice Improve Upper Extremity Motor Recovery after Stroke? A Systematic Review. ISRN Stroke 2014; 2014: 10.

77. Van Peppen RP, Kwakkel G, Wood-Dauphinee S, Hendriks HJ, Van der Wees PJ, Dekker J. The impact of physical therapy on functional outcomes after stroke: what's the evidence? Clin Rehabil 2004; 18(8): 833-62.

78. Lee M, Saver JL, Hong KS, Song S, Chang KH, Ovbiagele B. Effect of pre-diabetes on future risk of stroke: meta-analysis. BMJ 2012; 344: e3564.

79. Miller EL, Murray L, Richards L, et al. Comprehensive overview of nursing and interdisciplinary rehabilitation care of the stroke patient: a scientific statement from the American Heart Association. Stroke 2010; 41(10): 2402-48.

80. Bakas T, Clark PC, Kelly-Hayes M, King RB, Lutz BJ, Miller EL. Evidence for stroke family caregiver and dyad interventions: a statement for healthcare professionals from the American Heart Association and American Stroke Association. Stroke 2014; 45(9): 2836-52.

81. Grant JS, Hunt CW, Steadman L. Common caregiver issues and nursing interventions after a stroke. Stroke 2014; 45(8): e151-3.

82. Kernan WN, Ovbiagele B, Black HR, et al. Guidelines for the prevention of stroke in patients with stroke and transient ischemic attack: a guideline for healthcare professionals from the American Heart Association/American Stroke Association. Stroke 2014; 45(7): 2160-236.

83. Fogarty International Center. Toolkit: Overcoming Barriers to Implementation in Global Health. $\quad$ https://www.fic.nih.gov/About/center-global-health-studies/neuroscienceimplementation-toolkit/Pages/default.aspx (accessed 30 Dec 2016).

84. Peters D, Tran N, Adam T. Implementation Research in Health: A Practical Guide. Geneva: World Health Organization, 2013.

85. Fogarty International Center. Learning Collaborative for Implementation Science in Global Brain Disorders. https://www.fic.nih.gov/About/center-global-healthstudies/Pages/learning-collaborative-implementation-science-global-brain-disorders.aspx (accessed 30 Dec 2016). 
86. World Health Organization. Everybody's business: strengthening health systems to improve health outcomes. WHO's Framework for Action. Geneva: WHO; 2007.

87. Mounier-Jack S, Griffiths UK, Closser S, Burchett H, Marchal B. Measuring the health systems impact of disease control programmes: a critical reflection on the WHO building blocks framework. BMC public health 2014; 14: 278.

88. Wolfe CD, Redfern J, Rudd AG, Grieve AP, Heuschmann PU, McKevitt C. Cluster randomized controlled trial of a patient and general practitioner intervention to improve the management of multiple risk factors after stroke: stop stroke. Stroke 2010; 41(11): 2470-6.

89. Aadal L, Angel S, Dreyer P, Langhorn L, Pedersen BB. Nursing roles and functions in the inpatient neurorehabilitation of stroke patients: a literature review. The Journal of neuroscience nursing : journal of the American Association of Neuroscience Nurses 2013; 45(3): 158-70.

90. Aho K, Harmsen P, Hatano S, Marquardsen J, Smirnov VE, Strasser T. Cerebrovascular disease in the community: results of a WHO collaborative study. Bulletin of the World Health Organization 1980; 58(1): 113-30.

91. Schumacher G. Culture care meanings, beliefs, and practices in Rural Dominican Republic. J Transcult Nurs 2010; 21(2): 93-103.

92. !!! INVALID CITATION !!! 82.

93. Cramer SC. Repairing the human brain after stroke: I. Mechanisms of spontaneous recovery. Ann Neurol 2008; 63(3): 272-87.

94. Kreisel SH, Hennerici MG, Bazner H. Pathophysiology of stroke rehabilitation: the natural course of clinical recovery, use-dependent plasticity and rehabilitative outcome. Cerebrovascular diseases 2007; 23(4): 243-55.

95. Paolucci S, Antonucci G, Grasso MG, et al. Functional outcome of ischemic and hemorrhagic stroke patients after inpatient rehabilitation: a matched comparison. Stroke 2003; 34(12): 2861-5.

96. Rothwell PM, Giles MF, Chandratheva A, et al. Effect of urgent treatment of transient ischaemic attack and minor stroke on early recurrent stroke (EXPRESS study): a prospective population-based sequential comparison. Lancet (London, England) 2007; 370(9596): 1432-42.

97. Mouradian MS, Majumdar SR, Senthilselvan A, Khan K, Shuaib A. How well are hypertension, hyperlipidemia, diabetes, and smoking managed after a stroke or transient ischemic attack? Stroke 2002; 33(6): 1656-9.

98. Ovbiagele B, Saver JL, Fredieu A, et al. In-hospital initiation of secondary stroke prevention therapies yields high rates of adherence at follow-up. Stroke 2004; 35(12): 2879-83.

99. Scholte op Reimer WJ, Dippel DW, Franke CL, et al. Quality of hospital and outpatient care after stroke or transient ischemic attack: insights from a stroke survey in the Netherlands. Stroke 2006; 37(7): 1844-9. 
4623 100. Dean N, Shuaib A. Transient ischaemic attacks: unstable, treatable, neglected. Lancet 624 (London, England) 2007; 370(9596): 1398-400.

625

101. Rumsfeld JS, Brooks SC, Aufderheide TP, et al. Use of Mobile Devices, Social Media, and Crowdsourcing as Digital Strategies to Improve Emergency Cardiovascular Care: A Scientific Statement From the American Heart Association. Circulation 2016; 134(8): e87-e108. 